\title{
EFEITO DA DIETA DURANTE O DESENVOLVIMENTO LARVAL DE MENIPPE NODIFRONS STIMPSON, 1859
}

\author{
Marochi, M.Z. ${ }^{1,}{ }^{*}$; Guarizo, M. ${ }^{1} \&$ Costa, T.M. ${ }^{1}$ \\ ${ }^{1}$ Universidade Estadual Paulista "Júlio de Mesquita Filho" (Unesp), Campus do Litoral Paulista, Instituto de \\ Biociências. Laboratório de Ecologia e Comportamento Animal (Labecom). \\ *Autor correspondente: murilo.marochi@gmail.com
}

\begin{abstract}
Estoques naturais de algumas espécies costeiras já estão próximo do limiar de sobre-exploração. O repovoamento destes ambientes pela liberação de larvas artificialmente incubadas surgiu nos últimos anos como uma técnica viável para a reparação e manutenção de estoques de espécies exploradas comercialmente. O desenvolvimento de dietas que forneçam requisitos nutricionais necessários para o desenvolvimento larval é um fator chave para criação com sucesso de métodos de recuperação populacional. Embora a cultura larval de Brachyura já apresente resultados positivos em algumas espécies, para a maioria não existem protocolos de alimentação tecnicamente e financeiramente viáveis. Neste sentido, o nosso objetivo foi avaliar o efeito de diferentes dietas durante o desenvolvimento larval de Menippe nodifrons. Cinco dietas foram avaliadas: as microalgas Tetraselmis gracilis, Chaetoceros calcitrans e Thalassiosira weissflogii, o rotífero Brachionos plicatilis e nauplius recém eclodidos de Artemia sp. Larvas zoea I, provenientes de seis fêmeas ovígeras, foram individualizadas em placas de cultura celular com poços de $5 \mathrm{ml}$, totalizando 96 réplicas para cada dieta. As placas de cultura celular foram mantidas em câmara de germinação a $25 \pm 1^{\circ} \mathrm{C}$ e fotoperíodo de $12: 12 \mathrm{~h}$ (claro: escuro). Diariamente a água dos poços era trocada e novo alimento era fornecido. Os dados de sobrevivência e desenvolvimento foram obtidos diariamente. A dieta afetou a sobrevivência das larvas. Cinquenta e três larvas alimentadas com rotíferos atingiram o estágio de zoea III, com um tempo médio de metamorfose até ZIII de $10.07 \pm 2.64$ dias e taxa de sobrevivência de $40 \%$. Cinco larvas alimentadas com nauplius de Artemia sp. sobreviveram até zoea III, com uma taxa de sobrevivência de 5\% e tempo de metamorfose até ZIII de 14,75 \pm 3.70 dias. A longevidade larval e desenvolvimento das dietas baseadas em microalgas foram curtos. Apenas o tratamento Tetraselmis gracilis avançou para ZII. Somente na dieta de Artemia sp. as larvas atingiram o estágio de megalopa. Baseado em nossos resultados, a dieta mais adequada ao desenvolvimento larval de Menippe nodifrons é uma combinação da dieta de Brachionos plicatilis durante os estágios iniciais e posterior introdução de Artemia sp. até o estágio de megalopa.
\end{abstract}

Palavras-chave: sobrevivência larval, Brachyura, estoques pesqueiros, microalgas. 